\begin{tabular}{|c|l|}
\hline Title & Performance characteristics and internal phenomena of polymer electrolyte membrane fuel cell with porous flow field \\
\hline Author(s) & Tabe, Yutaka; Nasu, Takuya; Morioka, Satoshi; Chikahisa, Takemi \\
\hline Citation & $\begin{array}{l}\text { Journal Of Power Sources, 238, 21-28 } \\
\text { https://doi.org/10.1016/.jpowsour.2013.03.047 }\end{array}$ \\
\hline Issue Date & 2013-09-15 \\
\hline Doc URL & http:/hdl.handle.net/2115/53681 \\
\hline Type & article (author version) \\
\hline File Information & Manuscript.pdf \\
\hline
\end{tabular}

Instructions for use 


\title{
Performance characteristics and internal phenomena of polymer electrolyte membrane fuel cell with porous flow field
}

Yutaka Tabe*, Takuya Nasu, Satoshi Morioka, Takemi Chikahisa

Division of Energy and Environmental Systems, Graduate School of Engineering, Hokkaido

University, N13 W8, Kita-ku, Sapporo 060-8628, Japan

* Corresponding author. Tel.: +81 11706 6381; fax: +81 117067889.

E-mail address: tabe@eng.hokudai.ac.jp; N13 W8, Kita-ku, Sapporo 060-8628, Japan.

\begin{abstract}
Polymer electrolyte membrane fuel cells (PEFC) with a porous flow field have been proposed as an alternative to cells with gas flow channels. In this study, the basic characteristics of a PEFC with a porous flow field are identified experimentally. It is shown that stable operation is maintained under conditions at high current density and low stoichiometric ratios of the cathode air, but that operation with low relative humidity gases is difficult in the porous type cell. To clarify the detailed causes of these characteristics, internal phenomena are investigated using a cell specially made for cross-section observations of the cathode porous flow field and temperature distribution measurements on the anode gas diffusion layer (GDL) surface. The direct observations show that the porous type cell is superior in draining the condensed water from the GDL surface, and that hydrophilic properties of the porous material is important for better cell performance at high current densities. The temperature measurements indicate that increases in temperature near the reaction area tends to be larger in the porous type cell than in the channel type cell due to the lower heat removal capability of the porous material, resulting in the unstable operation at relatively low humidities.
\end{abstract}

Keywords: PEM fuel cell, Porous flow field, Gas flow channel, Water management, Direct observation, Temperature distribution

\section{Introduction}

The polymer electrolyte membrane fuel cell (PEFC) is considered a potential candidate as a power source with high efficiency and clean emissions for automobiles and stationary distributed power supply systems. For the practical use of PEFC, it is important to realize uniform current densities across the reaction areas and to maintain high performance of the power generation, and also proper management of the water, the reactant gas flow, and the temperature in the cell is essential. This is because the membrane needs to be fully hydrated to maintain high proton conductivity while excess amounts of water condensed in the gas diffusion layers (GDLs) and gas flow channels impede the supply of reactants to the electrodes at high current density and low air flow rate conditions. Therefore, the gas flow field, which supplies the reaction gas and removes the produced water into and from the GDL, must be carefully designed with this in mind.

Gas channel and land configurations are commonly used to supply the reactant gases through the GDL to the reaction area, and the performance characteristics of cells with various 
types of gas flow channels have been investigated (for examples [1-3]). In addition to the conventional serpentine and straight channels [1], a conventional and interdigitated-switchable gas flow field was proposed to improve the cell performance under flooded conditions [2], and a self-draining stirred tank reactor cell was proposed for operations with low relative humidity gases [3]. To develop a detailed understanding of PEFC dynamics, a number of studies on the diagnostics of PEFC, such as on the measurement of the current density distribution and visualization of the water production behavior, have been conducted [3-9], and an overview was provided on the distributions of current density, high-frequency resistance, gas species and temperature, and including a two-phase visualization [1]. The effects of the distribution of the produced water and the gas composition on the cell performance were discussed using the measured results of the current density distribution [4,5], and the relationships between the local cell impedance and current density have also been investigated [3]. The water production behavior in the cathode gas flow channels has been investigated using a transparent fuel cell, and the relation between liquid water behavior and cell performance was demonstrated [6]. Liquid water removal from gas channels has also been characterized in detail [7]. The authors have observed phenomena related to water production behavior inside a cell, analyzed the effects on the current and temperature distributions across the reaction area [8], and reported the specific phenomena in the flow of condensed water and gas using cells with serpentine and straight channels [9]. Different from the channel and land configurations, porous flow fields have been proposed as an alternative to conventional flow channels, and a structure without channels is expected to enable realization of uniform reaction over the active area of the membrane electrode assembly [10]. Recently, performance and mass transport of a single cell with open metallic element flow field architecture have been investigated at ultra-high current densities under low humidity conditions [11]. To further develop cells with porous flow fields, a more detailed understanding of the cell characteristics under a broader range of conditions and an elucidation of factors influencing the cell performance is necessary.

The objective of this paper is to identify the basic characteristics of a cell with a porous flow field under high and low humidity conditions, and to clarify the internal phenomena in the cell and its effects on the cell performance. The cell characteristics with the porous flow field were investigated by comparing with serpentine and straight flow channels. Further, to measure the internal phenomena determining the identified characteristics, which are stable operation under flooded conditions and unstable operation under low relative humidity conditions, two types of single cells were specially modified and developed: one is for cross-sectional observations of the condensed water behavior in the porous flow field and the other is for temperature distribution measurements on the anode GDL surface. From these measurements, the detailed mechanisms determining the cell characteristics with porous flow fields are discussed.

\section{Experimental apparatus and methods}

Experiments were conducted with two single cells: Cell A was used for measurements of performance characteristics, and Cell B was used for the cross-sectional observations of the porous flow field and the temperature distribution measurements on the anode gas diffusion 
layer (GDL) surface. An outline of Cell A with an active area of $100 \mathrm{~cm}^{2}(10 \mathrm{~cm} \times 10 \mathrm{~cm})$ is shown in Fig. 1. A catalyst-coated membrane (CCM) with a $30 \mu \mathrm{m}$ thick polymer electrolyte membrane and two $10 \mu \mathrm{m}$ thick catalyst layers is sandwiched between the GDLs, flow plates and current collectors, and the end-plates of the cathode and anode sides. Here, $0.3 \mathrm{~mm}$ thick carbon paper with a micro porous layer on the CCM side was used for the GDLs, and flow plates with the porous flow field, serpentine channels (which will be shown in Fig. 5(b) below), and straight channels were used on the cathode side. A porous material (SUMITOMO ELECTRIC, Celmet) was inserted in the current collector for the porous flow field, as shown in the center of Fig. 1. The porous material (right in Fig. 1) was made of nickel, and the thickness and porosity were $1.4 \mathrm{~mm}$ and $97 \%$. The condensed water behavior on the surface of the porous material can be observed through a window in the cathode end-plate. The flow plates with serpentine or straight channels were made of copper overlaid with gold, and the width of the channels and lands of both plates were $2.0 \mathrm{~mm}$. The flow plates have open channels through which the GDL surfaces can be observed, and the thickness of the plates, which corresponds to the channel height, was $0.5 \mathrm{~mm}$ [9]. In the anode flow plate with straight channels, electrically insulated $5.5 \mathrm{~mm}$ diameter pins were placed at 25 points and the current density distribution was measured with the pins. Each pin was connected to a shunt resistance of $0.1 \Omega$ for the current measurements, and calibration was made with a variable resistance connected to each shunt resistance to compensate for contact resistance variations among the pins and to ensure uniform resistance over the whole area. The details of the calibration and analysis methods are in Reference (9).

An outline of Cell B with an active area of $25 \mathrm{~cm}^{2}(5 \mathrm{~cm} \times 5 \mathrm{~cm})$ is shown in Fig. 2. Cell $\mathrm{B}$ has a similar cathode structure, as Cell $\mathrm{A}$, and the outlet area of the cathode porous material is open, as shown in Fig. 2(a). The transport behavior of the liquid water inside the porous flow field was estimated by observing the edge face of the porous material from the red arrow in Fig. 2(a). An optical microscope (LEICA, Z16APO) was used for the direct observations, and the anode flow plate has no pins for the current density measurements. For temperature distribution measurements, the anode structure was changed to one similar to the cathode structure of Cell A with straight channels. An infrared-transparent sapphire glass was used as the anode window, and an infrared thermograph (NEC, TH5104R) was used for the temperature distribution measurements on the anode GDL (Fig. 2(b)). At the cathode side, current collectors without the open part and an end-plate without a window were used. The reasons why the temperature measurements were conducted from the anode side are to make it possible to observe the same surface directly in the vicinity of the reaction area with different cathode types and to diminish the influence of emissivity changes, arising from the condensed water, on the temperature measurements, because of the drier conditions at the anode side during the operation.

In the experiments, the cell was set vertically as suggested in Figs. 1 and 2, and placed in thermostatic chambers. A water-cooled plate placed on the anode side was used to maintain a constant cell temperature during long period operation only in Cell A (not shown in Fig. 1). The reactant gases, pure hydrogen as the anode gas and air (oxygen $21 \%$, nitrogen $79 \%$ ) as the cathode gas, were supplied in the same direction, and the gas humidity was controlled by the bubbler temperature. The cell resistance was measured by an alternating impedance meter 
at the impedance of $1 \mathrm{kHz}$, and the cell voltage, impedance, pressure drop, and current densities (actual voltage at the shunt resistance) were recorded on a computer.

\section{Results and discussion}

\subsection{Performance characteristics of the cell with porous flow field}

Cell A, with a $100 \mathrm{~cm}^{2}$ active area (Fig. 1), and with three types of cathode flow fields was investigated, the porous flow field, serpentine channels, and straight channels (in the following porous type, serpentine type, and straight type cells). The polarization curves for the porous and the serpentine type cells are shown in Fig. 3. The relative humidity $(\mathrm{RH})$ of both anode hydrogen and cathode air was $100 \%$ at the saturation temperature of $70{ }^{\circ} \mathrm{C}$, with the cell temperature at $70^{\circ} \mathrm{C}$. The anode hydrogen was supplied at the stoichiometric ratio of 2.5 . The flow rate of the cathode air was at two relatively-low stoichiometric ratios, $\lambda=1.4$ and 2.0, to investigate the cell characteristics under flooded conditions. The measurements applied a constant current which was increased from $0.0 \mathrm{~A}$, and the stable voltage after operation for a couple of minutes at a constant current was plotted. The porous type cell can operate up to 0.7 $\mathrm{A} \mathrm{cm}^{-2}$ with the smaller cathode flow rate of the 1.4 stoichiometric ratio, while the cell voltage drops steeply about over $0.6 \mathrm{~A} \mathrm{~cm}^{-2}$ due to the concentration overpotential (Fig. 3). The voltage of the porous type cell at the 2.0 stoichiometric ratio is higher than at the lower stoichiometric ratio, 1.4, and decreases more slowly by the decrease in concentration overpotential. The measurement of the polarization curve was impossible at the lower stoichiometric ratio, 1.4, with the serpentine type cell. At the higher stoichiometric ratio, 2.0, the voltages of the serpentine type cell are higher than in the porous cathode cell but drops below it in the high current density region. Here, the lower voltage of the porous type cell in the medium current density region is mainly a result of higher cell resistance. The measured cell resistances at $0.4 \mathrm{~A} \mathrm{~cm}^{-2}$ were $0.6 \Omega \mathrm{cm}^{2}$ and $0.3 \Omega \mathrm{cm}^{2}$ for the porous and the serpentine type cells. The calculated overpotentials by the ohmic resistance loss were $0.2 \mathrm{~V}$ and $0.1 \mathrm{~V}$, respectively, and this voltage difference of about $0.1 \mathrm{~V}$ corresponds to that at $0.4 \mathrm{~A} \mathrm{~cm}^{-2}$ in Fig. 3. The higher cell resistance of the porous type cell is estimated to be caused by problems of the cell structure used in this study and the high contact resistance between the porous material and the cathode current collector. The results indicate that the porous type cell offers advantages at high current density and low stoichiometric operation under flooded conditions. It is estimated that the lower cell voltage of the porous type cell in the medium current density region can be improved by decreasing the high contact resistance between the porous material and the other parts of the cell.

Fig. 4 shows the changes in the cell voltage and the pressure drop in the cathode gas after the start of the power generation in the porous, the serpentine, and the straight type cells. The overall current density was $0.7 \mathrm{~A} \mathrm{~cm}^{-2}$ with the anode hydrogen and the cathode air supplied at the stoichiometric ratio of 2.5 , and the humidity of both gases $100 \% \mathrm{RH}$ at the saturation temperature for $70{ }^{\circ} \mathrm{C}$, with the cell temperature at $70{ }^{\circ} \mathrm{C}$. As the experiments progress, the cell voltage of the serpentine type cell reaches a stable value around $500 \mathrm{~s}$ and then the high and stable voltage is maintained. The porous type cell also operates stably for the long period of time recorded here, although the voltage is lower than the serpentine cell, due to the higher 
cell resistance, the cell voltage of the straight type cell decreases gradually with large fluctuations, indicating the poorer drainage of condensed water in the straight channels [9]. The poorer drainage in the straight channels is caused by the slower air flow velocity which is about one fifth of that in the serpentine channels, although the velocity in the porous flow field is estimated to be slower than that in the straight channels. The pressure drop of the cathode gas shows that the long serpentine channel with the high-velocity air induces an extremely high pressure drop in the serpentine type cell, and the pressure drop in the porous type cell is suppressed to a lower level, similar to that in the straight type cell (Fig. 4). These data show that the porous type cell provides superior drainage of the condensed water in the cell and also stable operation with small fluctuations by only the low pressure drop of the cathode gas.

Fig. 5 are examples of direct views of the cathode side (left panels) and the current density distributions (right panels) in the porous and the serpentine type cells at the steady state after a long period operation. Here, the current density differences between the measured value at each point and the average value for the 25 pins are represented as a ratio of the average value. The overall current density was $0.7 \mathrm{~A} \mathrm{~cm}^{-2}$, the cell temperature was $70{ }^{\circ} \mathrm{C}$, and both of the anode hydrogen and the cathode air were supplied at the stoichiometric ratio of 2.0 with $100 \% \mathrm{RH}$. Liquid water was observed in the serpentine channels and at the surface of the porous flow field in the downstream area, enclosed with dashed lines in Fig. 5 (left panels). Comparing the current density distributions (right panels), the current density of the serpentine type cell is lower in the downstream area, while the porous type cell has a more uniform current density distribution. One reason for the non-uniform density distribution in the serpentine type cell is the characteristic that the variation in the current density easily becomes large because of shortcut flows through the GDL under the land areas [9]. These results suggest that the porous type cell is not affected by the unevenness resulting from the channel and land configurations of the serpentine type cell, and the condensed water in the porous flow field does not deteriorate the cell performance. Section 3.2 below investigates the transport mechanism of the condensed water inside of the porous flow field by observing the condensed water behavior in the porous material, and discusses reasons why the cell performance here is less affected by the condensed water.

The cell characteristics at relatively low humidities were investigated by decreasing the bubbler temperature, $T_{b}$, from $70{ }^{\circ} \mathrm{C}$ to 50 and $40{ }^{\circ} \mathrm{C}$. Fig. 6 shows the cell voltage and resistance changes after the start of the power generation in the porous and the straight type cells. The straight type cell is considered to be tolerant to low RH operations, providing the poorer drainage of condensed water as shown by Fig. 4, because the larger amounts of accumulated water increase the humidity of the supply gases and prevent the membrane resistance from the increases that occur in drier states. The overall current density was $0.4 \mathrm{~A}$ $\mathrm{cm}^{-2}$, with both of the anode hydrogen and the cathode air supplied at the stoichiometric ratio of 2.5. Because the cell performance is sensitive to the cell temperature with low RH gases supplied, both kinds of cells were operated at the same temperature control conditions for the thermostatic chamber temperature, the cooling water temperature, and flow rate. As a result, the cell temperatures were maintained at $72{ }^{\circ} \mathrm{C}$ and $70{ }^{\circ} \mathrm{C}$ in the porous and the straight type cells respectively. In the straight type cell, the condensed water affects the cell voltage, which fluctuates at the high humidity condition with the bubbler temperature, $T_{b}$, at $70{ }^{\circ} \mathrm{C}$, the cell voltage is stable at the lower humidity condition, $T_{b}=50{ }^{\circ} \mathrm{C}$, and is further decreased at the 
lowest humidity condition, $T_{b}=40{ }^{\circ} \mathrm{C}$. The voltage decrease is estimated to be due to increases in the cell resistance arising from the low humidity in the polymer electrolyte membrane under the lower humidity condition. The lower humidity effect becomes larger in the porous type cell: the cell voltage decreases significantly with lower humidities and this is considered to be caused by the low humidity of the membrane. These results indicate that the polymer electrolyte membrane in the porous type cell is more affected by drying, it is accompanied by an increase in the cell resistance, and the porous type cell suffers from this disadvantage under low humidity conditions. The large influence of the humidity change on the cell performance would be also a disadvantage for practical transient operation of a fuel cell. Section 3.3 reports the temperature distribution over the anode GDL surface, and discusses why the membrane dries more easily and the cell resistance tends to increase under low humidity conditions in the porous type cell.

\subsection{Transport mechanism of the condensed water inside the porous flow field}

In section 3.1, it was shown that the porous type cell provides superior drainage of the produced water and that the cell performance is less affected by the condensed water in the cell. In this section, the transport mechanism of the condensed water inside the porous flow field was investigated by observing the condensed water behavior in the porous material using Cell B with a $25 \mathrm{~cm}^{2}$ active area (Fig. 2(a)). Fig. 7 shows direct views of the condensed water in cross-sections of the porous material at four different times after the start of droplets emerging from the GDL, $t=0 \mathrm{~s}$. The overall current density was $0.4 \mathrm{~A} \mathrm{~cm}^{-2}$. Here, pure hydrogen was supplied to the anode side at the stoichiometric ratio of 5.4, and the stoichiometric ratio of the cathode air was 2.7 . The humidity of both gases was $100 \% \mathrm{RH}$ at the saturation temperature of $45{ }^{\circ} \mathrm{C}$, and the cell temperature was also $45{ }^{\circ} \mathrm{C}$ at the start of operation. In Fig. 7, the condensed water is enclosed with white lines. The behavior of the condensed water inside the porous flow field in Fig. 7 will be explained together with the schematic outlines of the transport mechanism in Fig. 8. After about $190 \mathrm{~s}$ from the start of the power generation, the condensed water becomes visible at specific locations of the GDL surface (left side in each picture), as shown in Figs. 7(b) and 8(a). Because the condensed water flows selectively into the relatively-wide throats and pores inside the hydrophobic GDL [12], there is not a lot of visible condensed water on the GDL surface. After the water volume has grown (Fig. 7(c)) and is touching the fibers of the porous material, the water droplet spreads along the fibers to form the water film, here the condensed water is attracted from the GDL to the fiber surfaces (Figs. 7(d) and 8(b)). This is because the porous material of the fibers (nickel) has hydrophilic characteristics. It is estimated that the condensed water present along the fibers is drained by the air flow without plugging (blocking) the porous flow field and that a dynamic equilibrium is maintained (Fig. 8(c)), resulting in the tolerance to flooding in the porous type cell. These observations provide visible substantiation of the reasons why the porous type cell is superior in the drainage of the generated water from the surface of the GDL, and suggest that the hydrophilic property of the porous material is an important factor in this tolerance to flooding. To confirm the transport mechanism and its effect on the cell performance as outlined above, direct observations of the cross-section were conducted using a porous material coated with water repellant, and the performance characteristics of the cells 
with the ordinary hydrophilic and the hydrophobic porous materials were compared. Fig. 9 shows direct views of condensed water in cross-sections of the hydrophobic porous material. The operating conditions are the same as in the experiment of Fig. 7. The discharge of condensed water from the GDL surface starts in Fig. 9(b). The water droplet, however, remains on the GDL surface and grows very large after touching the hydrophobic fiber (Fig. 9(c)). Although the water droplet grows large compared with the pore size of the porous material (Figs. 9(c) and (d)) as the droplet is pushed out from the porous material to the exit, the water droplet inside of the porous flow field is estimated to remain on the GDL surface, even in contact with the fibers. This suggests that the hydrophobic properties of the fiber of the porous material here hinders the water drainage performance from the GDL surface in the porous type cell. Fig. 10 shows the cell voltage change after the start of the power generation in the hydrophilic and the hydrophobic porous materials using Cell A. The overall current density was $0.7 \mathrm{~A} \mathrm{~cm}^{-2}$, and the cell temperature was $70^{\circ} \mathrm{C}$, these experiments (Fig. 10) used pure oxygen as the cathode gas, and the anode hydrogen and the cathode oxygen were supplied at the stoichiometric ratio of 2.0 with $100 \% \mathrm{RH}$. As the experiments progress, the stable operation is maintained in the cell with the hydrophilic porous material as also found previously (Fig. 4), while there are fluctuations in the voltage in the cell with the hydrophobic porous material. This is estimated to be related to the droplet behavior emerging from the GDL surface, as shown in Fig. 9; the condensed water is prone to remain on the GDL surface and disturbs the reaction gas supply into the GDL in the cell with the hydrophobic porous material.

From these experiments, it was confirmed that the emerging condensed water is immediately removed from the GDL surface to the other side of the porous flow field and that the porous type cell has excellent water removal from the GDL surface. This results in the efficient supply of gas into the GDL under flooded conditions, and realizes stable operation with small fluctuations at high current density and low stoichiometric operation. It may be also concluded that hydrophilic property of the porous material is an important factor in the tolerance to flooding in the porous type cell.

\subsection{Temperature in-plane distribution under low humidity condition}

The temperature distribution measurements were conducted with low humidity supply gases using Cell B, the setup was that outlined in Fig. 2(b). The cell voltage and resistance changes of the porous and the straight type cells are shown in Fig. 11. The overall current density was $0.7 \mathrm{~A} \mathrm{~cm}^{-2}$, anode hydrogen and cathode air were supplied at the stoichiometric ratio of 4.0. The humidity of both gases was $34 \% \mathrm{RH}$ at the saturation temperature for $25^{\circ} \mathrm{C}$, with the cell temperature at $45{ }^{\circ} \mathrm{C}$ at the start of operation. The cell voltage and resistance of the straight type cell are nearly constant even with the low humidity supply gases here. With the porous type cell, the cell resistance increases and the cell voltage decreases gradually, and the operation shuts down around $1100 \mathrm{~s}$. This corresponds to the characteristics of the porous type cell, discussed in section 3.1 (Fig. 6), that the membrane easily dries out and the cell resistance increases under low humidity conditions.

To investigate the cause of the decrease in water content of the membrane in the porous type cell, the temperature distributions on the anode GDL surface in the Fig. 11 experiments 
were analyzed. Fig. 12(a) shows the results of the temperature measurements in the porous type cell at two time points after the start of operation, $5 \mathrm{~min}$ and $15 \mathrm{~min}(3 \mathrm{~min}$ before the shutdown at $18 \mathrm{~min}$ ). The temperature distribution is striped because straight open channels were used at the anode side, and the emissivities of the GDL and the flow plate were different, the higher temperature parts correspond to the GDL surfaces, and lower temperature parts correspond to the land surfaces of the flow plate. Here, Cell B was operated without anode water-cooled plate. The temperature increases gradually and the distribution is non-uniform at 15 min: the temperature in the downstream area (right sides of panels in Fig. 12(a)) is higher than that upstream. This can be explained by the humidification of the supply gases resulting from the produced water. The humidity of the supply gas is increased by the produced water present along the porous flow field, the resistance of the polymer electrolyte membrane is decreased by the high humidity gases, and that increases the current density with more heat produced in the downstream area. The temperature-changes at two points, $a$ near the gas inlet and $b$ near the outlet in the left of the panels of Fig. 12(a), are shown in Fig. 12(b) for the porous and the straight type cells. The temperature of the porous type cell increases steeply after the start of operation and becomes about $5{ }^{\circ} \mathrm{C}$ higher than that of the straight type cell. This is considered to be due to the low thermal conductivity of the porous material with the very high porosity of $97 \%$ and the high contact thermal resistance between the porous material and the other parts of the cell for similar reasons as the increase in contact electric resistance. Comparing the temperatures at the two points in the cells, the temperature at $b$, near the exit, is higher in the porous type cell as explained by Fig. 12(a), while the temperature at $a$, near the inlet, is higher in the straight type cell. In the straight type cell, the small increase in the temperature makes the cell resistance less likely to be affected by the decrease in the membrane water content, and the high oxygen concentration in the upstream area may dominate the power generation performance, resulting in more heat produced near the inlet. After further operation in the straight type cell, at $50 \mathrm{~min}$, there was an inversion of the $a$ and $b$ temperatures at $62{ }^{\circ} \mathrm{C}$ (not shown in Fig. 12(b)), and after this the temperature at $b$ became higher like the situation in the porous type cell. These changes indicate that the dominant factor in the cell performance changes from the oxygen concentration of the cathode gas to the membrane wetness state when the cell temperature increases over a certain value and the relative humidity of the supply gases decreases. One reason why the inversion point, $62{ }^{\circ} \mathrm{C}$, in the straight type cell is higher than that in the porous type cell, $57^{\circ} \mathrm{C}$ in Fig. $12(\mathrm{~b})$, is that the land structure disturbs the water drainage from the GDL to the gas channels $[13,14]$ and contributes to a water retention effect near the membrane. From these results, it can be concluded that the ease of increase in the cell resistance in the porous type cell under low humidity conditions is caused by the poor thermal transport property of the porous type cell and increase in the membrane temperature. This disadvantage can be improved by increasing the thermal conductivity of the porous material such as by decreasing the porosity and reducing the high contact thermal resistance between the porous material and the other parts of the cell.

In this study, the advantage under flooded conditions and the disadvantage under low humidity conditions were confirmed in the porous type cell using a nickel porous material, 1.4 $\mathrm{mm}$ thick, $97 \%$ porosity. Decreasing the porosity and the thickness of the porous material is effective to improve the thermal transport property of the porous type cell and is estimated to 
have less impact on the good tolerance to flooding because of the condensed water transport mechanism discussed in section 3.2. Decreasing the porosity and the thickness of the porous material, however, increases the pressure drop of the cathode gas and may induce plugging of the flow of condensed water in the porous flow field. That means that appropriate design of the porous type cell is needed paying careful attention to the intended use.

\section{Conclusions}

The basic characteristics of a PEFC with a porous flow field (porous type cell) are identified experimentally, and the internal phenomena causing the characteristics were investigated by cross-section observations of the porous flow field and temperature distribution measurements on the anode gas diffusion layer surface. The major conclusions may be summarized as follows:

1. The porous type cell is tolerant to flooding and has advantages in high current density and low stoichiometric operation. The structure of the porous flow field realizes superior drainage performance of the water condensed in the cell and stable operation with only small fluctuations due to the limited pressure drop of the cathode gas. The polymer electrolyte membrane in the porous type cell is more prone to drying out, and this is accompanied by an increase in the cell resistance under low humidity conditions.

2. In the porous type cell condensed water is directly removed, away from the GDL surface, by the fibers of the porous material and this ensures an efficient and steady supply of gas to the GDL under flooded conditions, with a resulting stable operation with only small fluctuations in high current density and low stoichiometric operation. Hydrophilic properties of the porous material contribute significantly to the flooding tolerance of the porous type cell.

3. The ease of increase in the cell resistance in the porous type cell under low humidity conditions is caused by the poor thermal transport property of the porous type cell and the increase in the membrane temperature. To overcome this it will be necessary to increase the low thermal conductivity of porous material with critically high porosity such as by decreasing the porosity and to decrease the high contact thermal resistance between the porous material and the other parts of the cell.

\section{Acknowledgments}

This research was partly conducted as a collaborative project with Hitachi Ltd. The authors thank the researchers participating in this work for helpful comments on the experiments.

\section{References}

[1] C.-Y. Wang, Chem. Rev. 104 (10) (2004) 4727-4766.

[2] H. Yamada, T. Hatanaka, H. Murata, Y. Morimoto, J. Electrochem. Soc. 153 (9) (2006) A1748-A1754.

[3] W.H.J. Hogarth, J. Steiner, J.B. Benziger, A. Hakenjos, J. Power Sources 164 (2007) 464-471. 
[4] M. Noponen, J. Ihonen, A. Lundblad, G. Lindbergh, J. Appl. Electrochem. 34 (2004) 255-262.

[5] Z. Liu, Z. Mao, B. Wu, L. Wang, V.M. Schmidt, J. Power Sources 141 (2005) 205-210.

[6] K. Tüber, D. Pócza, C. Hebling, J. Power Sources 124 (2003) 403-414.

[7] F.Y. Zhang, X.G. Yang, and C.-Y. Wang, J. Electrochem. Soc. 153 (2) (2006) A225-A232.

[8] T. Chikahisa, Y. Tabe, K. Kikuta, N. Nohara, H. Shinohara, Proceedings of the 4th International Conference on Fuel Cell Science, Engineering and Technology [1/1 (CD-ROM) 97016], 2006, pp. 1-6.

[9] Y. Tabe, K. Kikuta, T. Chikahisa, M. Kozakai, J. Power Sources 193 (2009) 416-424.

[10] A. Kumar, R.G. Reddy, J. Power Sources 129 (2004) 62-67.

[11] A.K. Srouji, L.J. Zheng, R. Dross, A. Turhan, M.M. Mench, J. Power Sources 218 (2012) 341-347.

[12] Y. Tabe, Y. Lee, T. Chikahisa, M. Kozakai, J. Power Sources 193 (2009) 24-31.

[13] A. Turhan, K. Heller, J.S. Brenizer, M.M. Mench, J. Power Sources 160 (2006) $1195-1203$.

[14] S.N. Kyaw-Swar, Y. Tabe, T. Chikahisa, J. Power Sources, 196 (2011) 2584-2594. 
Fig. 1. Experimental arrangement for visual observations and current density measurements, Cell A.

Fig. 2. Experimental arrangement for Cell B, (a) for visual observations of porous cross-section and (b) for temperature measurements.

Fig. 3. Polarization curves for the cells with the porous flow field and the serpentine channels.

Fig. 4. Cell voltages and pressure drops in the cathode flow for three different flow field types, the porous, the serpentine and the straight channels.

Fig. 5. Direct view of the cathode sides (left side of panels) and current density distribution (right side of panels) in the cell with (a) the porous flow field and (b) the serpentine channels.

Fig. 6. Cell voltages for different relative humidities of supply gases for the cells with the porous flow field and the straight channels.

Fig. 7. Direct view of liquid water transport in the cross-section of the hydrophilic porous material, times are after start of droplets emerging from the GDL.

Fig. 8. Schematic representation of the transport mechanism of condensed water inside the porous flow field from start of operation (left) to stable operation (right).

Fig. 9. Direct view of liquid water transport in the cross-section of the hydrophobic porous material, times are after start of droplets emerging from GDL.

Fig. 10. Cell voltages with the ordinary hydrophilic and with the hydrophobic porous materials.

Fig. 11. Cell voltages and resistances of the cells with the porous flow field and the straight channels under low relative humidity condition.

Fig. 12. (a) Temperature distribution of the cell with the porous flow field at two times after start of operation, and (b) temperature changes at two points, $a$ and $b$, for the cells with the porous flow field and the straight channels. 


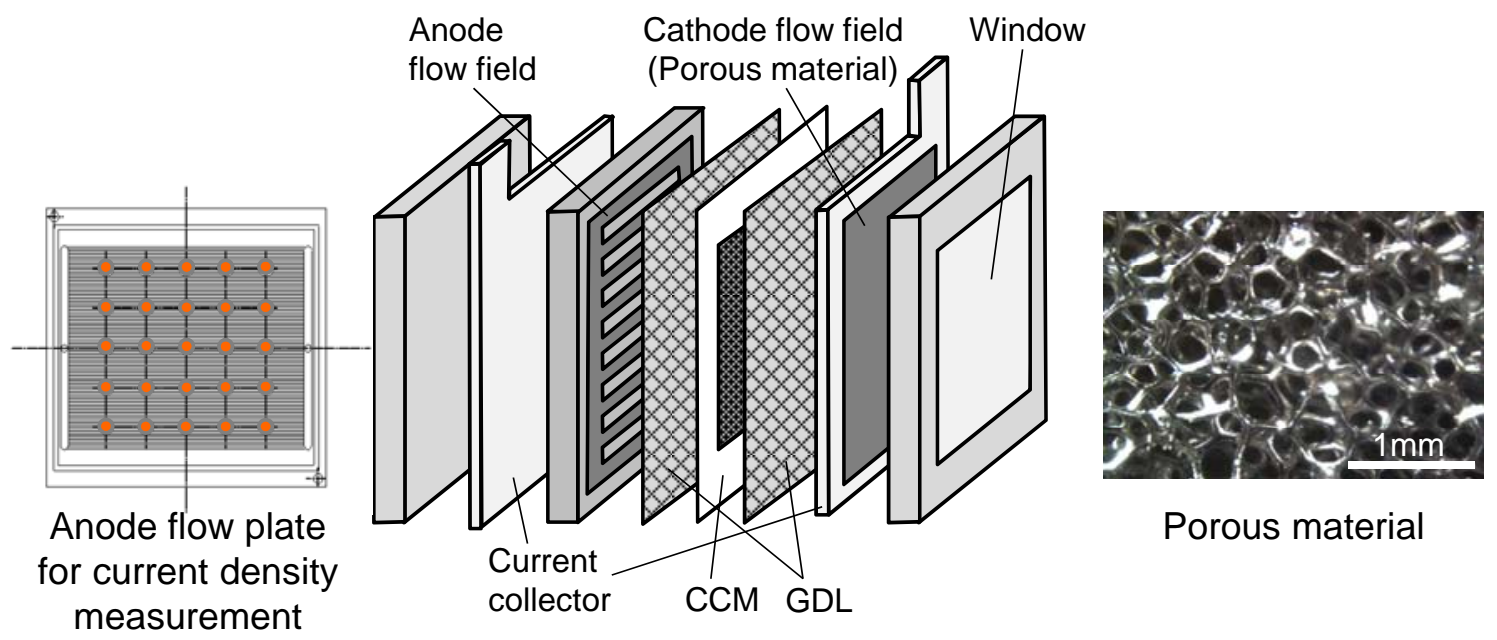

Fig. 1. Experimental arrangement for visual observations and current density measurements, Cell A. 
(a)

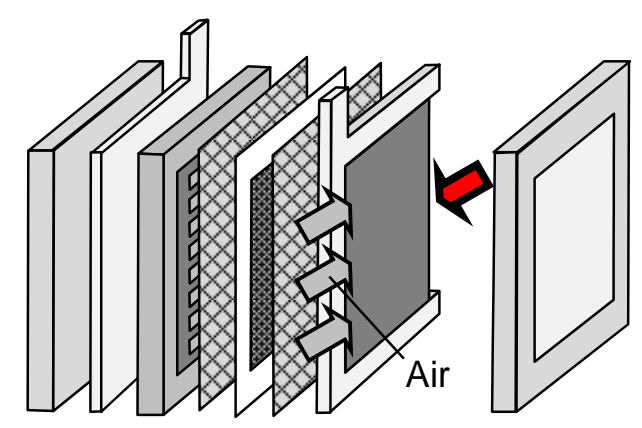

(b)

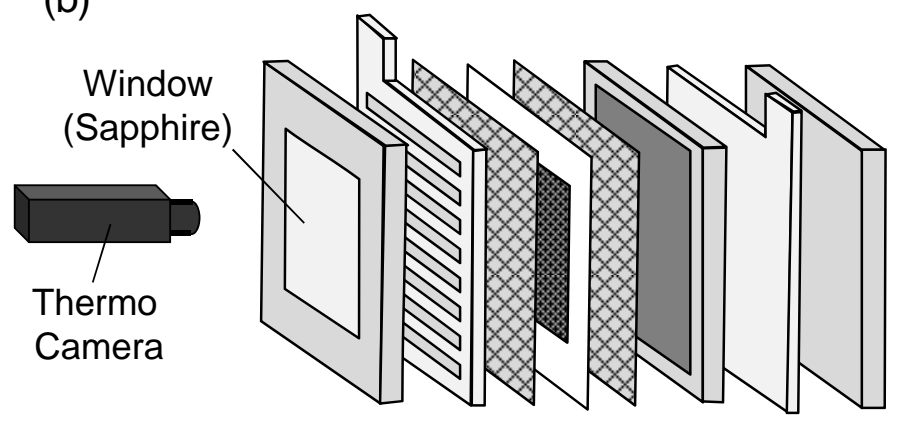

Fig. 2. Experimental arrangement for Cell B, (a) for visual observations of porous cross-section and (b) for temperature measurements. 


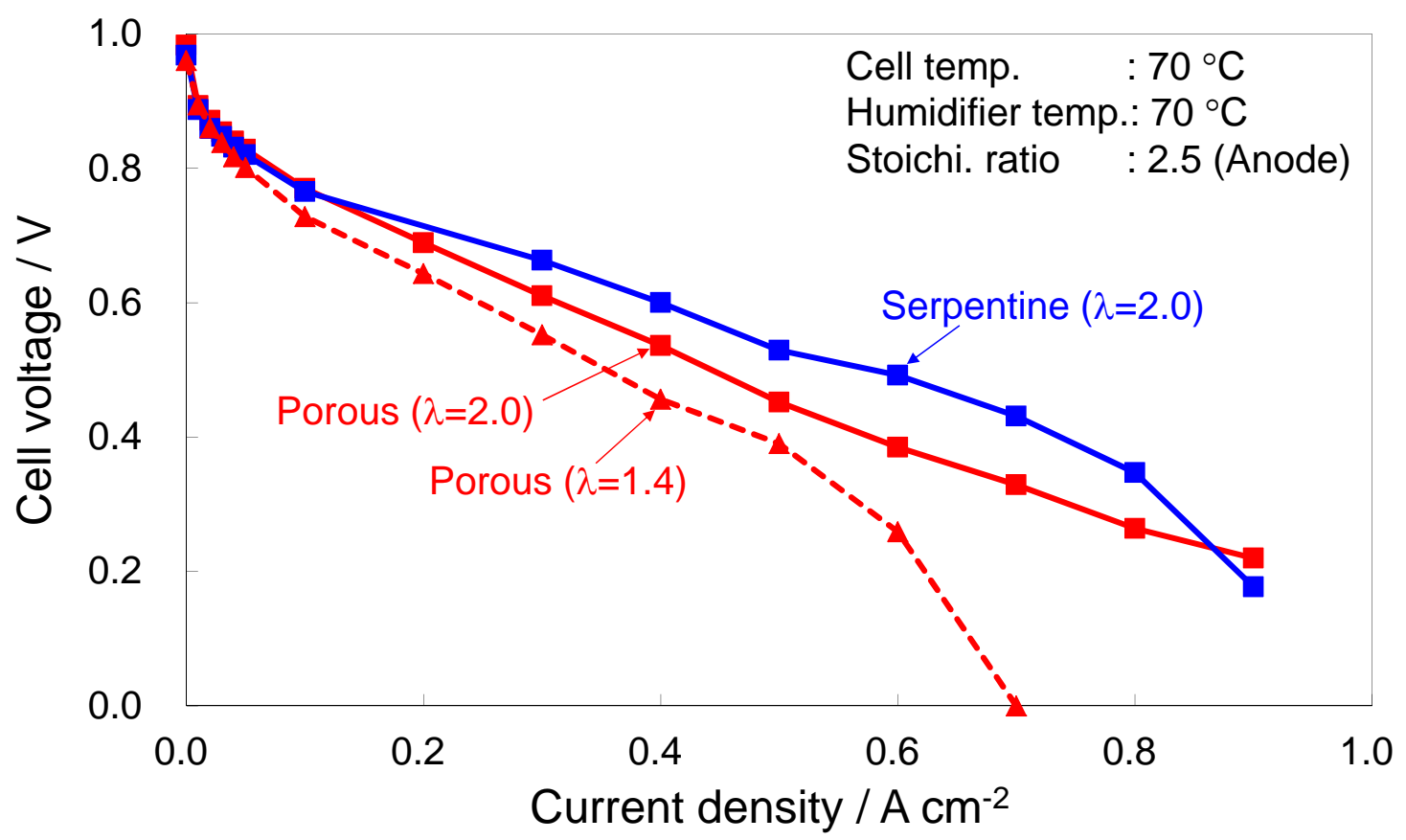

Fig. 3. Polarization curves for the cells with the porous flow field and the serpentine channels. 


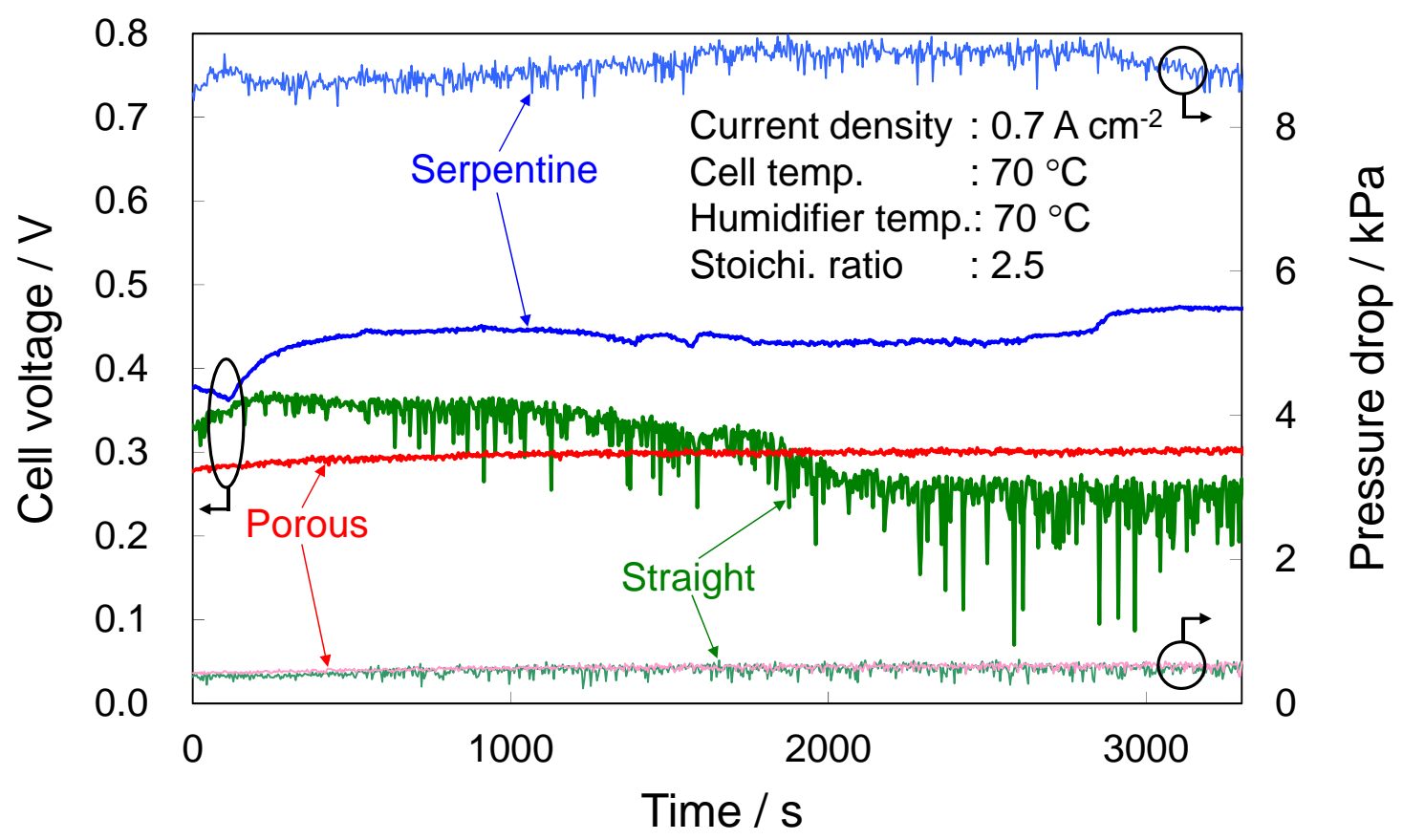

Fig. 4. Cell voltages and pressure drops in the cathode flow for three different flow field types, the porous, the serpentine and the straight channels. 
(a)

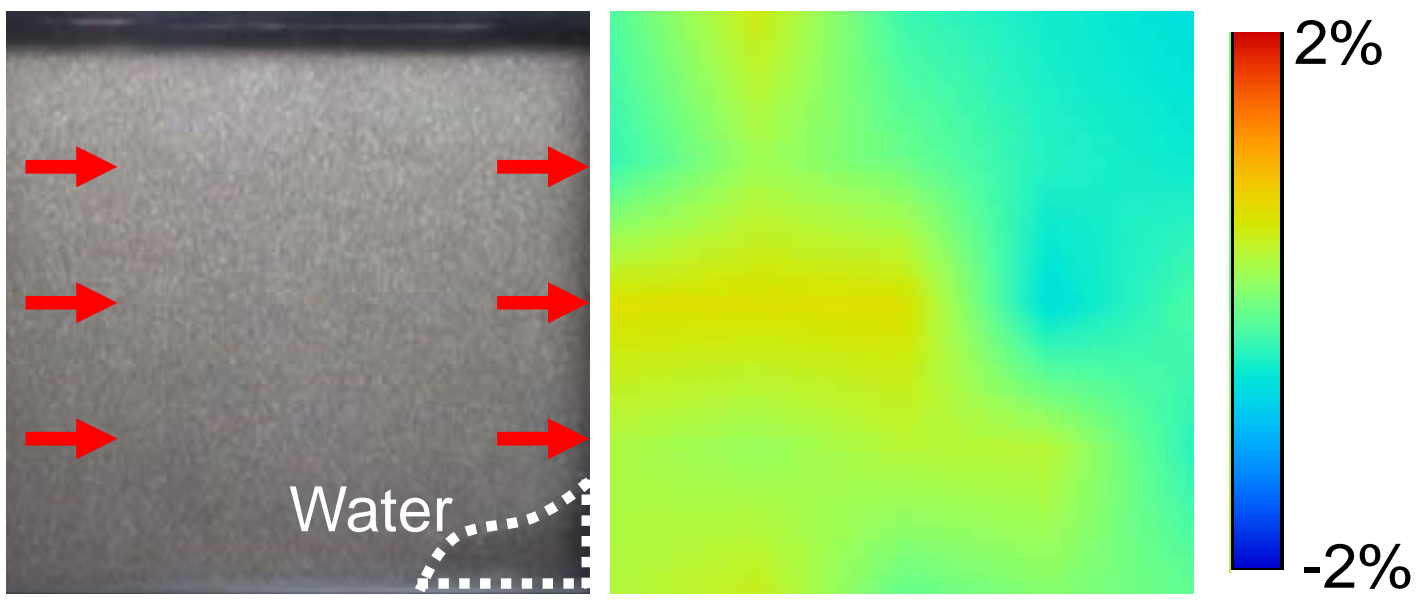

(b)
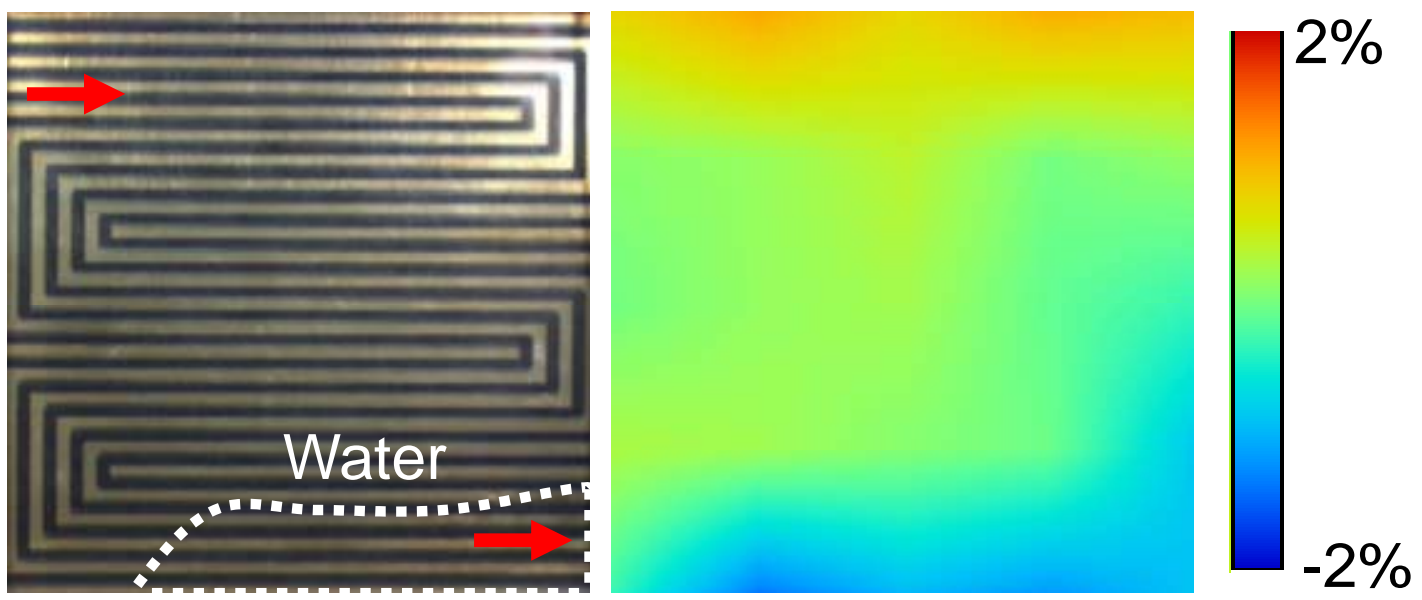

Fig. 5. Direct view of the cathode sides (left side of panels) and current density distribution (right side of panels) in the cell with (a) the porous flow field and (b) the serpentine channels. 


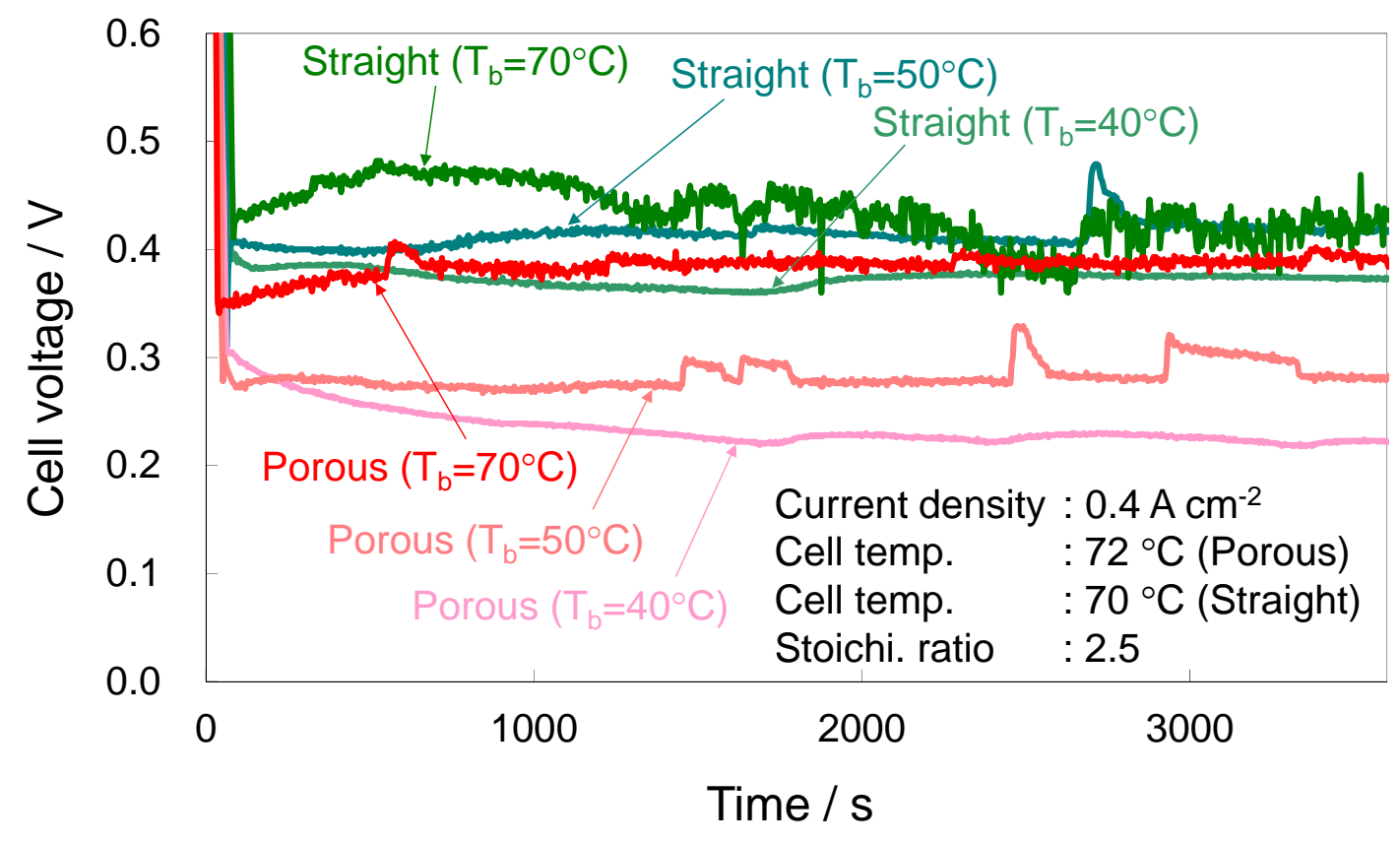

Fig. 6. Cell voltages for different relative humidities of supply gases for the cells with the porous flow field and the straight channels. 


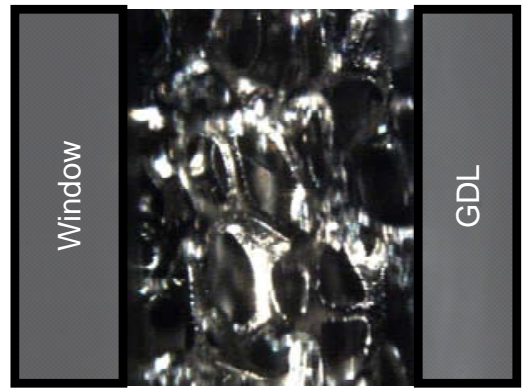

(a) $0 \mathrm{~s}$

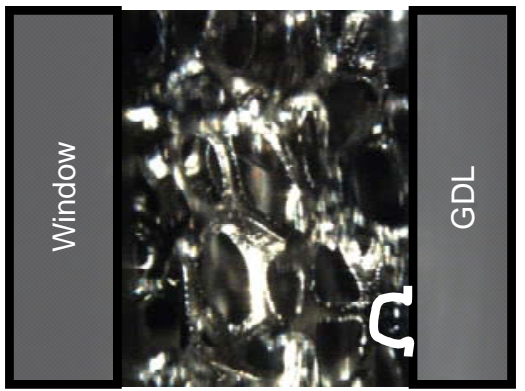

(c) $4.2 \mathrm{~s}$

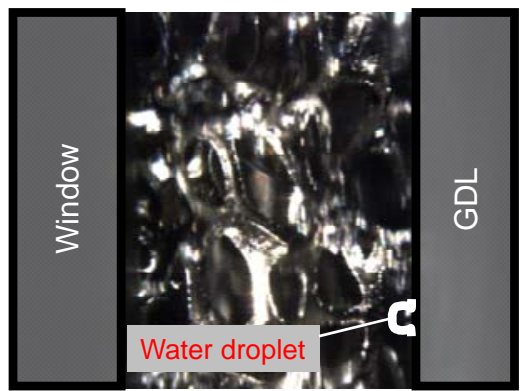

(b) $0.1 \mathrm{~s}$

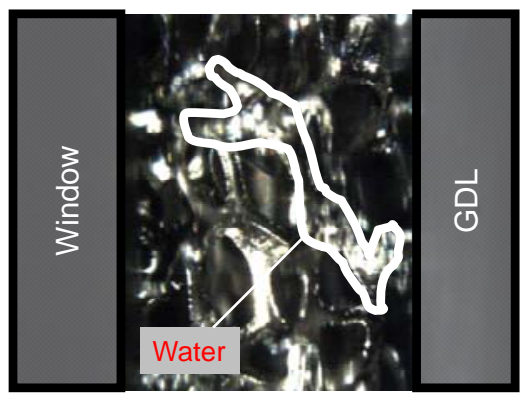

(d) $4.5 \mathrm{~s}$

Fig. 7. Direct view of liquid water transport in the cross-section of the hydrophilic porous material, times are after start of droplets emerging from the GDL. 


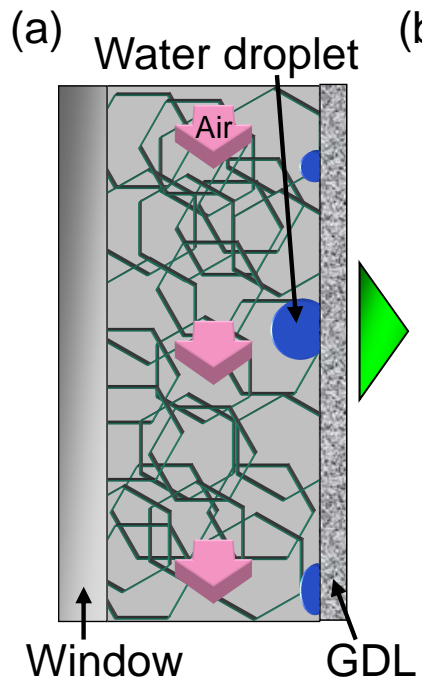

(b)

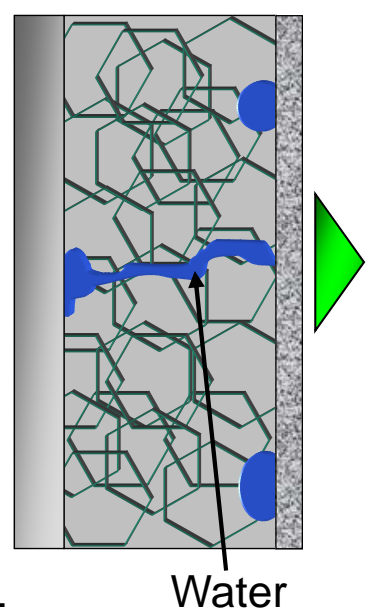

(c)

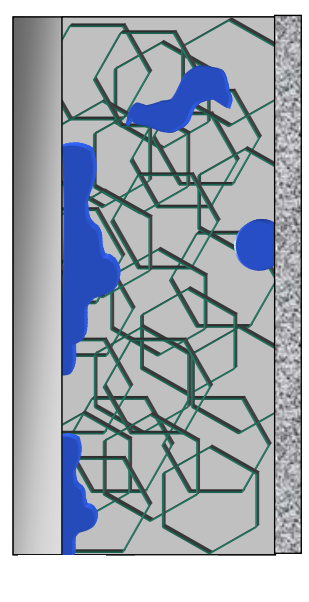

Fig. 8. Schematic representation of the transport mechanism of condensed water inside the porous flow field from start of operation (left) to stable operation (right). 


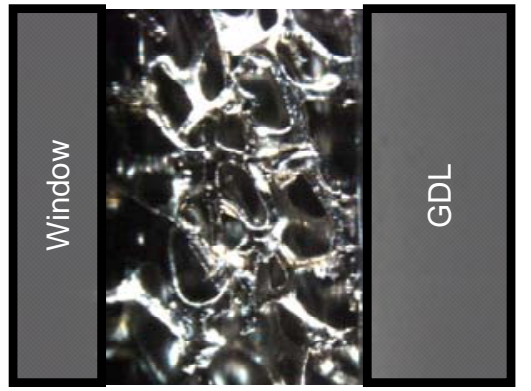

(a) $0 \mathrm{~s}$

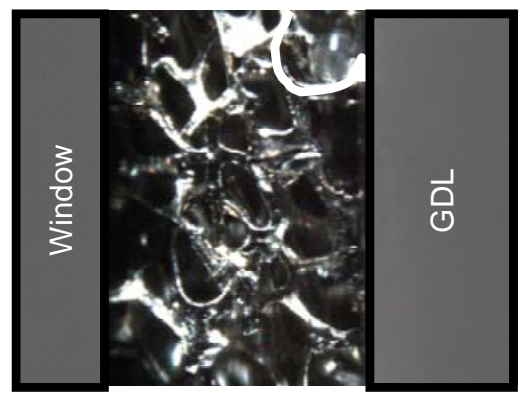

(c) $145.5 \mathrm{~s}$

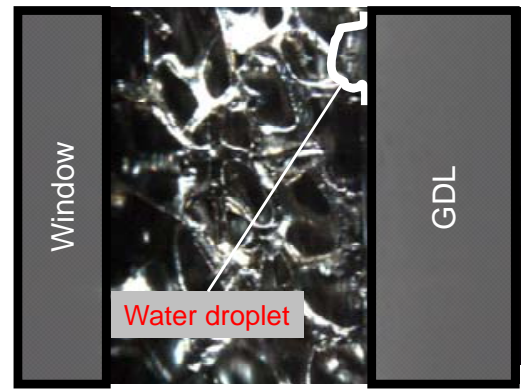

(b) $0.6 \mathrm{~s}$

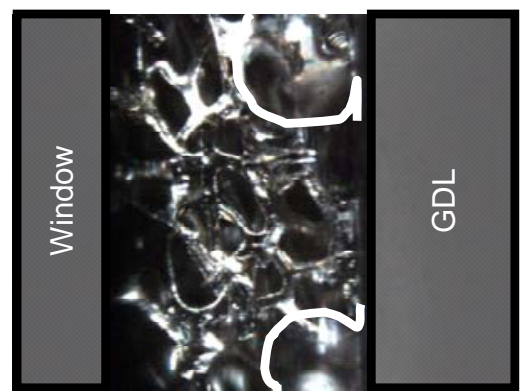

(d) $352.5 \mathrm{~s}$

Fig. 9. Direct view of liquid water transport in the cross-section of the hydrophobic porous material, times are after start of droplets emerging from GDL. 


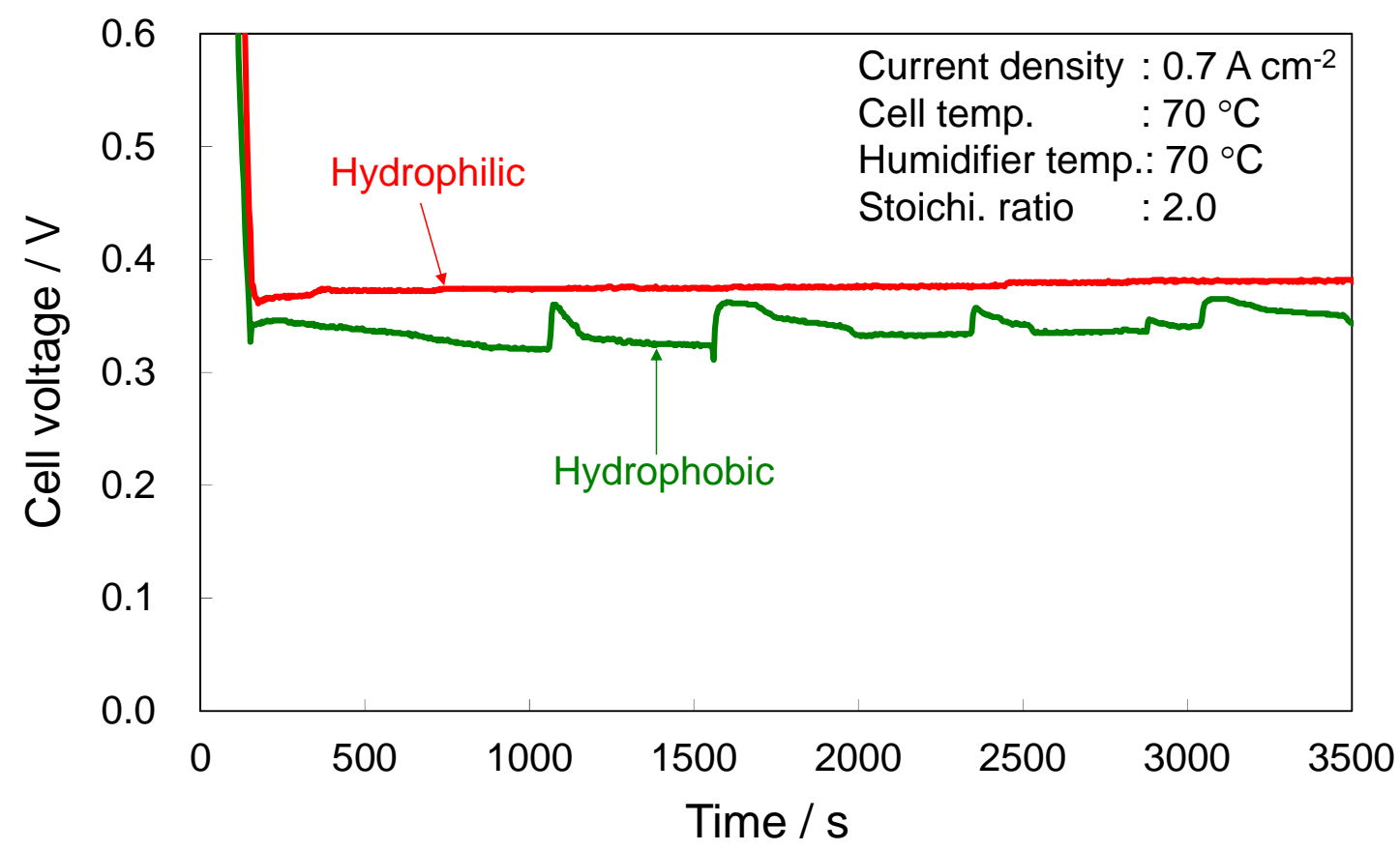

Fig. 10. Cell voltages with the ordinary hydrophilic and with the hydrophobic porous materials. 


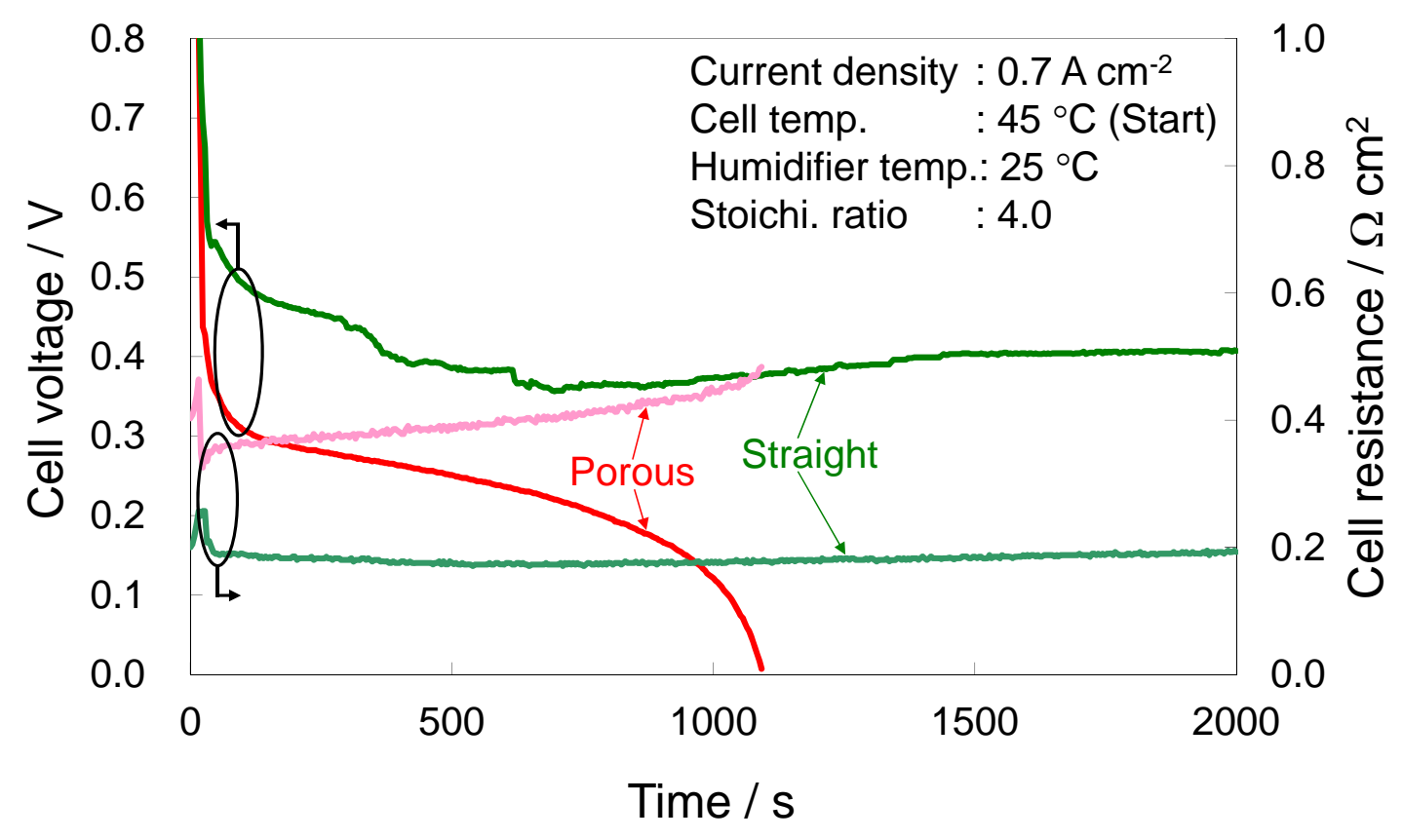

Fig. 11. Cell voltages and resistances of the cells with the porous flow field and the straight channels under low relative humidity condition. 
(a)

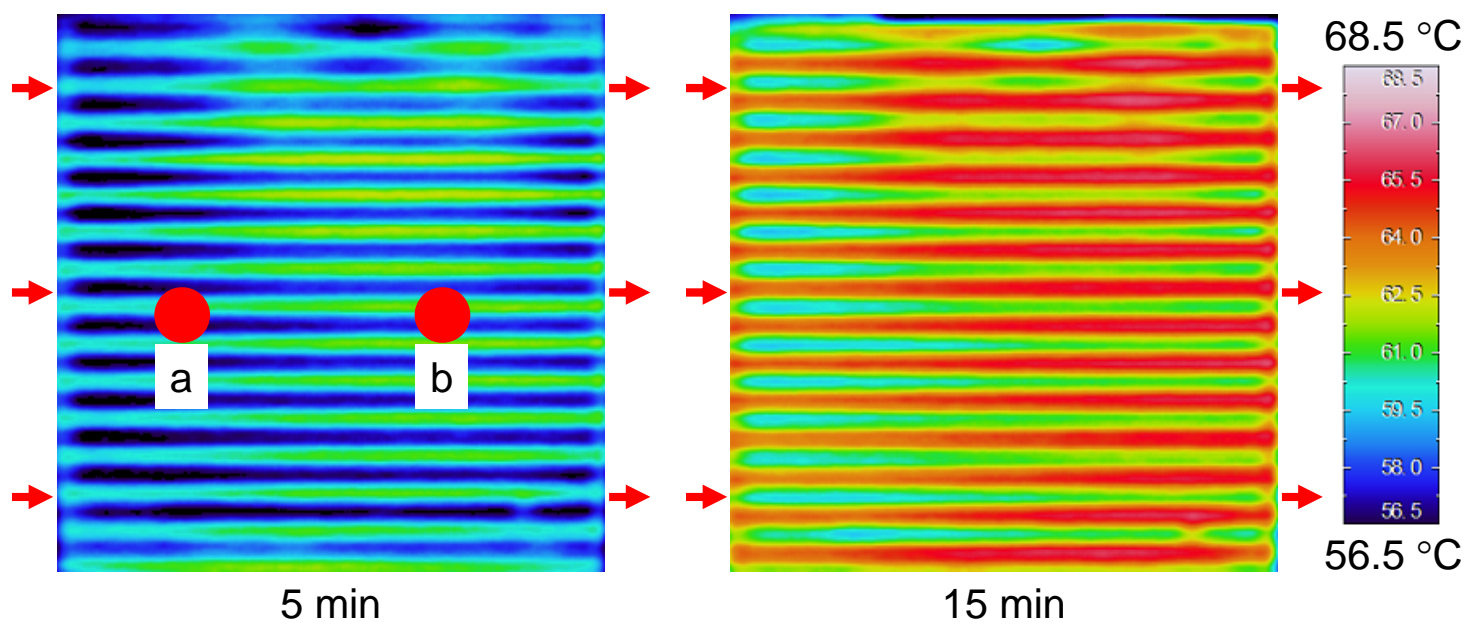

(b)

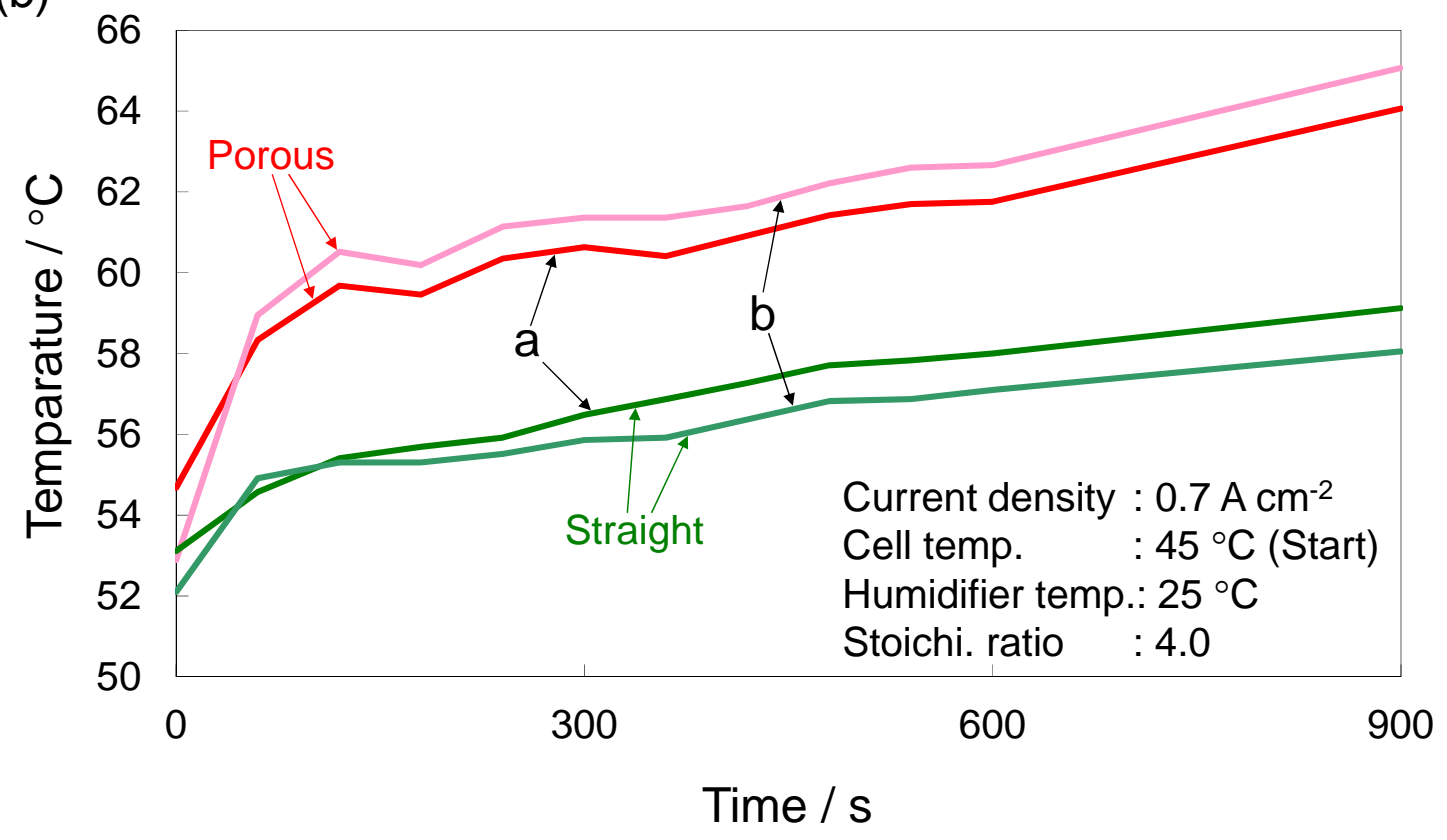

Fig. 12. (a) Temperature distribution of the cell with the porous flow field at two times after start of operation, and (b) temperature changes at two points, $a$ and $b$, for the cells with the porous flow field and the straight channels. 